\title{
Erratum to "Endoscopic Spine Surgery" by Choi G, et al. (J Korean Neurosurg Soc 60 : 485-497, 2017)
}

https://doi.org/10.3340/jkns.2017.0203.004

In this article by Choi $\mathrm{G}$ et al, the author would like to acknowledge that Fig. 5 was taken from the source : https://www.you-

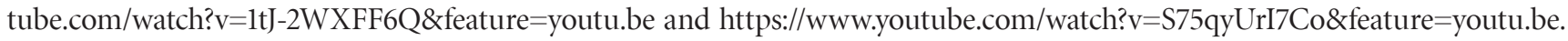
These videos are of the patients operated by Dr. Hyeun Sung Kim, Neurosurgery Specialist / Vice President of Suwon Nanoori Hospital, South Korea. For publishing these pictures in the manuscript, necessary permission had been taken.

On the page 490, the legend of Fig. 5 should be corrected as follow.
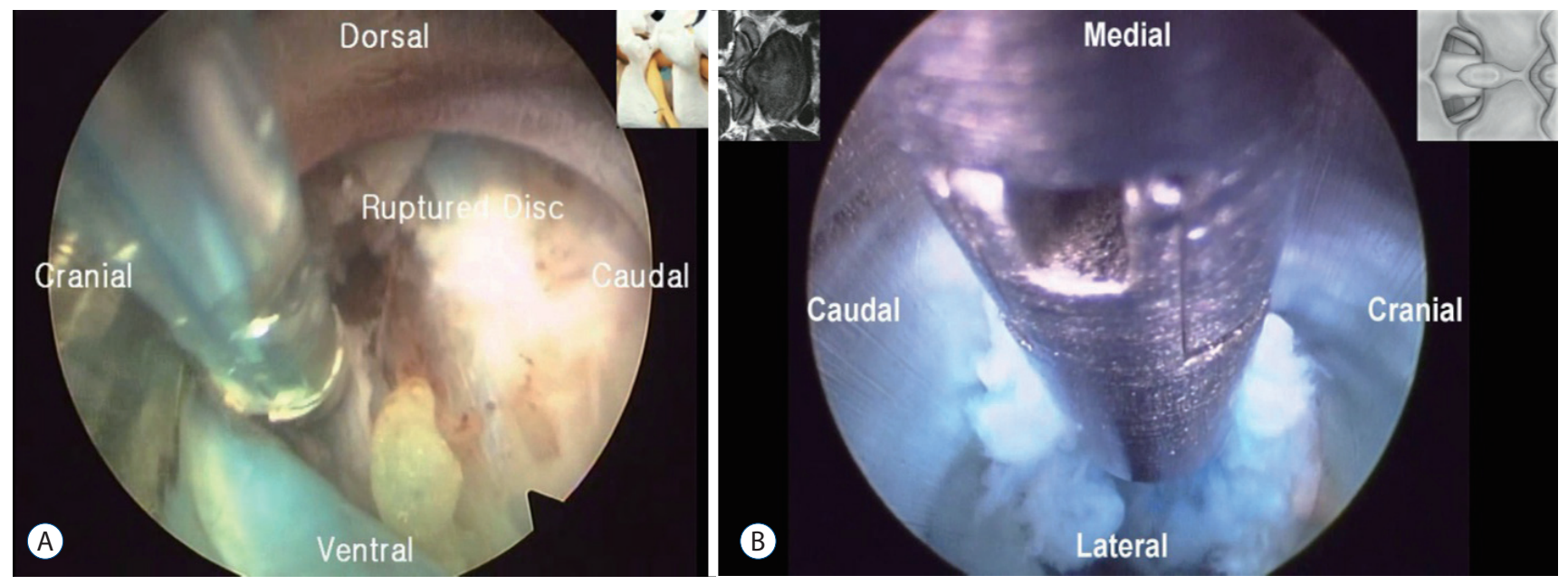

Fig. 5. A and B : Endoscopic view ${ }^{23,24)}$.

Also, on page 497, References should be added as below.

23. Kim HS : Percutaneous Endoscopic Transforaminal Lumbar Discectomy (PETLD) by Dr. Hyeun Sung Kim-01. Available at : https://www.youtube.com/watch?v=1tJ-2WXFF6Q\&feature=youtu.be

24. Kim HS : Percutaneous Endoscopic Interlaminar Lumbar Discectomy (PEILD) by Dr. Hyeun Sung Kim-01. Available at : https://www.youtube.com/watch?v=S75qyUrI7Co\&feature=youtu.be 